\title{
OPTIMIZATION OF THE OPERATION OF THE SELICE WATER STRUCTURE ON THE VÁH RIVER WITH REGARD TO NAVIGATIONAL SAFETY
}

\author{
${ }^{1}$ Anna PAVLÍKOVÁ, ${ }^{2}$ Ludovít MOŽIEŠIK \\ Department of Hydraulic Engineering, Faculty of Civil Engineering, Slovak University of \\ Technology in Bratislava, Radlinského 11, 81005 Bratislava, Slovakia \\ e-mail: ${ }^{1}$ anna.pavlikova@ stuba.sk, ${ }^{2}$ ludovit.moziesik@stuba.sk
}

Received 27 December 2015; accepted 15 June 2016

\begin{abstract}
The Selice water structure is situated on the lower Váh River. Within the frame of its preparation there was no hydraulic research conducted on the design of the layout of the structure and the nautical conditions for vessels approaching the water structure. The work deals with an evaluation of the parameters of the water flow and their impact on a vessel at the entrance to the approaches to the lock chamber in terms of navigational safety. Different scenarios have interpreted the passing of flows over the Selice water structure. Based on interpretations of the simulations, recommendations for the optimal operation of the water structure have been proposed with regard to navigational safety.
\end{abstract}

Keywords: Mathematical modeling, Navigational safety, Selice water structure, Váh River

\section{Introduction}

The security of the fairway parameters in the range of navigable flows is a necessary condition for ensuring navigational safety. Fairway parameters include: the depth and width of the fairway, the headroom height, arc radius, hydraulic characteristics, expansion of the fairway in a curve, and the rate of the water flow.

This article deals with an evaluation of the parameters of the water flow in terms of navigational safety in the area of an existing water structure (the Selice water structure), specifically, the entrances to the lock approaches and related recommendations for the optimal operation of the Water Structure (WS) [1], [2].

To achieve sufficient maneuverability of a vessel navigating downstream, the vessel must move faster than the water flow runs. Vessels reduce their ability to maneuver in 
areas where they reduce their speed before stopping (lock approaches, ports) [3]. The safe velocities of water flows are smaller in these areas than they are in ordinary areas of waterways.

The values of the transverse components of the velocities of water flows that force vessels out of an ideal fairway are also important for navigational safety, as they can cause the collision of the vessel with the fairway facility or another vessel. According to the recommendations of the Ministry of Transport of the Czech Republic, the indicative limit value of the transverse components of velocities is $0.2-0.3 \mathrm{~m} . \mathrm{s}^{-1}$. The values of the longitudinal components of velocities must be within a safe range, so that the vessel is able to brake sufficiently and safely before stopping.

Within the frame of the preparation of the Selice WS, no hydraulic research was undertaken on the design of the layout and the nautical conditions for vessels approaching the WS [4].

Therefore, the aim of this article is an evaluation of the parameters of the water flow's velocity field in the area of the Selice WS in terms of navigational safety, using the possibilities of two dimensional mathematical modeling.

\section{The Selice water structure on the Váh River}

The river Váh, a sinistral tributary of the Danube River [5], forms part of the Trans European Transport Network. The Selice WS is situated on the lower Váh at river km 43.90. It was not completed according to the original project.

The current state of the Selice WS is shown in Fig. 1. Originally, the gated weir should have been completed into the left bank of the Váh, so the fixed weir should not be part of the water structure at all (Fig. 2).

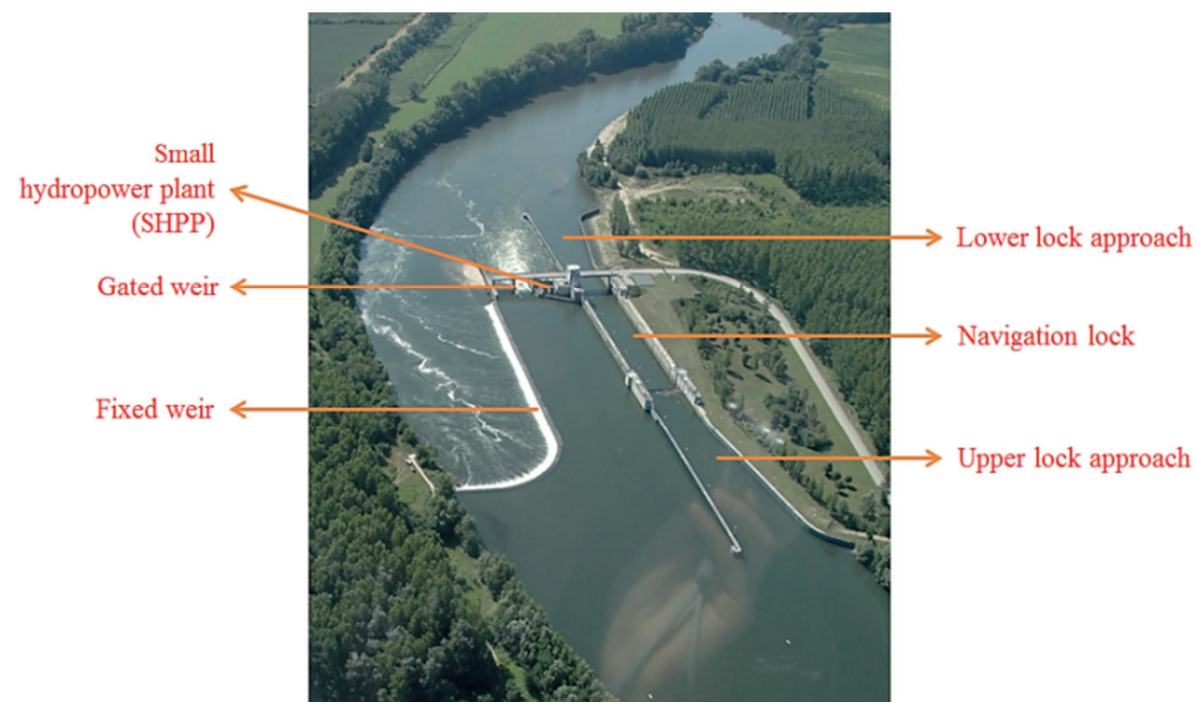

Fig. 1. The Selice WS in its current state (photo: Možiešik) 

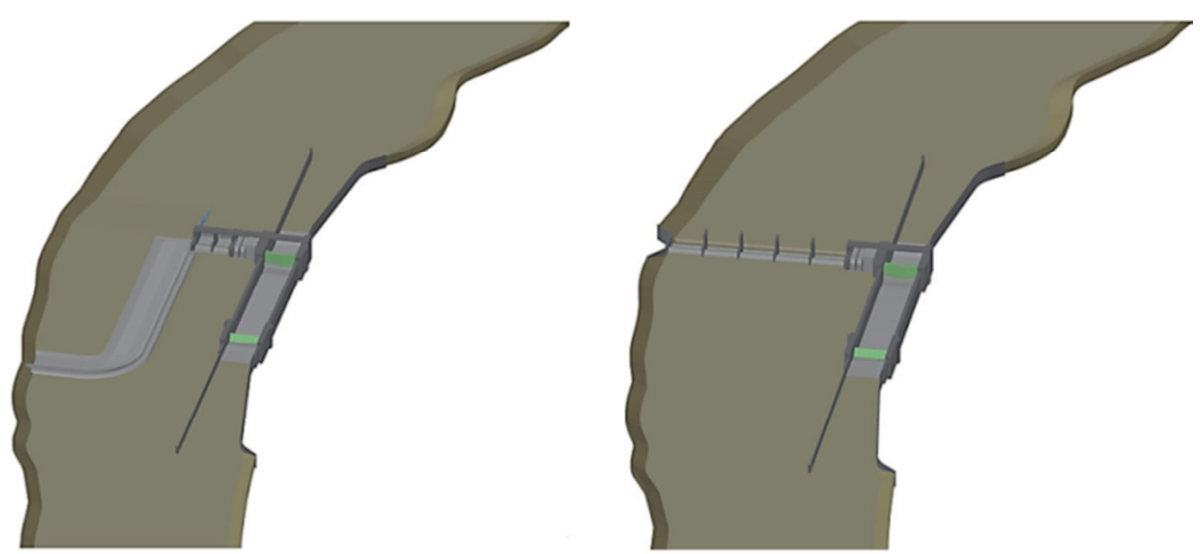

Fig. 2. 3D models of the Selice WS (left: the current state; right: the projected state)

\section{Evaluation of the parameters of the water flow's velocity field in the area of the Selice WS in terms of navigational safety}

The flow regime of the Selice WS depends on the operation of the upper water structure, the WS Král'ová.

The parameters of the water flow's velocity field were evaluated in various scenarios of the passing of the flow over the WS in its current state and in its projected state (Table I). The highest navigable discharge $\left(420 \mathrm{~m}^{3} \cdot \mathrm{s}^{-1}\right)$, which is the most unfavorable aspect in terms of navigational safety, was considered.

\section{Table I}

Scenarios of the passing of the flow over the Selice WS

\begin{tabular}{|l|c|c|}
\hline \multirow{2}{*}{ Scenario } & The current state of the WS & The projected state of the WS \\
\cline { 2 - 3 } & \multicolumn{2}{|c|}{ The highest navigable discharge is passed over: } \\
\hline I & The fixed weir & - \\
II & The fixed and gated weir & - \\
III & - & All the gates \\
IV & - & 3 right gates* \\
V & - & 3 left gates* \\
VI & - & 2 right gates* \\
VII & - & 2 left gates* \\
\hline VIII & - & All the gates and through the \\
\hline
\end{tabular}

$*$ in the direction of the water flow 


\subsection{Mathematical modeling (River 2D)}

Mathematical modeling was used to apply the free River 2D two-dimensional depth averaged finite element hydrodynamic model developed at the University of Alberta. The hydrodynamic component of the River2D model is based on the two-dimensional, depth averaged St. Venant Equations expressed in conservative form. These are continuity equation (1), equation of conservation of $x$-direction momentum (2) and equation of conservation of $y$-direction momentum (3),

$$
\begin{aligned}
& \frac{\partial H}{\partial t}+\frac{\partial q_{x}}{\partial x}+\frac{\partial q_{y}}{\partial y}=0, \\
& \frac{\partial q_{x}}{\partial t}+\frac{\partial}{\partial x}\left(U q_{x}\right)+\frac{\partial}{\partial y}\left(V q_{x}\right)+\frac{g}{2} \frac{\partial}{\partial x} H^{2} \\
& =g H\left(S_{0 x}-S_{f x}\right)+\frac{1}{\rho} \frac{\partial}{\partial x}\left(H \tau_{x x}\right)+\frac{1}{\rho} \frac{\partial}{\partial y}\left(H \tau_{x y}\right), \\
& \frac{\partial q_{y}}{\partial t}+\frac{\partial}{\partial x}\left(U q_{y}\right)+\frac{\partial}{\partial y}\left(V q_{y}\right)+\frac{g}{2} \frac{\partial}{\partial y} H^{2} \\
& =g H\left(S_{0 y}-S_{f y}\right)+\frac{1}{\rho} \frac{\partial}{\partial x}\left(H \tau_{y x}\right)+\frac{1}{\rho} \frac{\partial}{\partial y}\left(H \tau_{y y}\right),
\end{aligned}
$$

where $t$ is the time; $H$ is the depth of flow; $U$ and $V$ are the depth averaged velocities in the $x$ and $y$ coordinate directions respectively; $g$ is the gravitation acceleration; $\rho$ is the density of water; $S_{0}$ is the slope of channel bed; $S_{f}$ is the friction slope and $\tau$ is the depthaveraged transverse turbulent shear stress. The variables $q_{x}$ and $q_{y}$ are the components of the unit discharge, which are related to the velocity components $\left(q_{x}=H . U, q_{y}=H . V\right)$ [6].

The Finite Element Method (FEM) is used at which the mesh consists of triangular elements [7], [8]. The number of elements has to be higher in locations of hydraulic structures involved in passing the flow. The bed elevation is in the locations of weirs suddenly changed, which requires higher number of elements in comparison to the other parts of the model. This is necessary to be done, because the River2D, as a two dimensional model, evaluates hydraulics characteristics (e.g. velocities, components of the unit discharge...) only in horizontal level (axes $x$ and $y$ ) and the sudden bed changes in vertical level may cause difficulties during the computation process, if the mesh is not sufficiently dense. Increasing the mesh density (number of elements), the correctness of the computed characteristics is increasing too. Because of that, it is also important to add mesh elements to the areas of interest. In the case of reviewing the areas near by water structures in terms of navigational safety, they are the areas where a vessel enters the lock approaches. The number of elements is also limited with computer memory. All of this considered; the various simulated scenarios have various numbers of elements. The number of elements created during the simulations of the scenarios of the projected states of the WS was around 20000 , because they did not contain a fixed 
weir as a part of the water structure. However, the number of elements created during the simulation of the scenario of passing the flow over fixed weir in the current state of the WS was 93528 elements (48 136 nodes).

In Fig. 3 an output of the River 2D displays the computed water flow velocities (in $\mathrm{m} . \mathrm{s}^{-1}$ ) represented by the color scale and also by the velocity vectors. The velocity vectors provide information about the size and the direction of the water flow velocities in selected points.
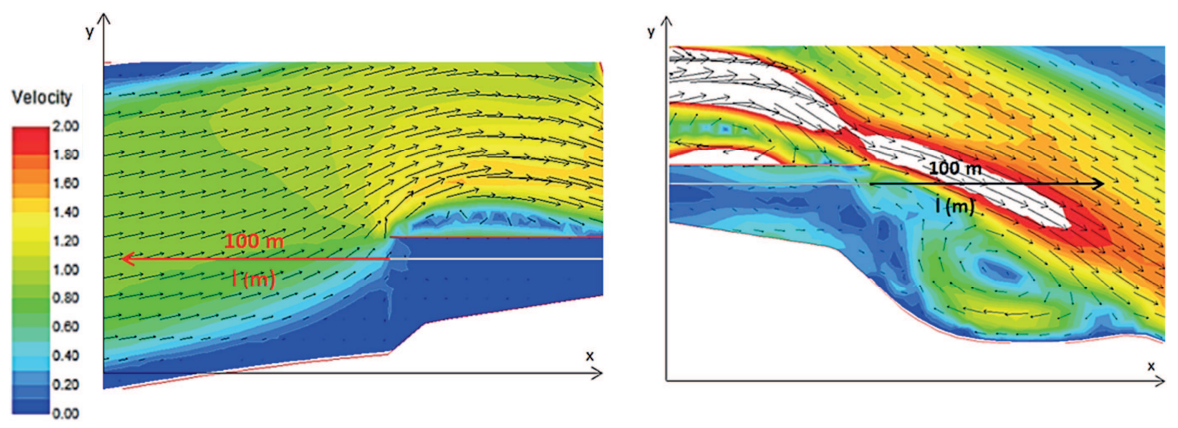

Fig. 3. Sections evaluated (left: the upper lock approach; right: the lower lock approach)

\subsection{Sections evaluated}

Whereas the navigational chamber of the Selice WS meets the maximum allowable dimensions for the international navigability class VIa, the velocity components were evaluated in a $100 \mathrm{~m}$ length section before a vessel enters the lock approaches (the maximum length of a vessel navigating the waterway class VIa is 95-110 m) [9], [10], [11], [12] as is shown in Fig. 3.

These sections are parallel to the $x$-axis, so that the velocity components acting in the $\mathrm{x}$-axis direction affect the vessel's trajectory in a longitudinal direction, and the velocity components acting in the $y$-axis direction affect the vessel's trajectory in a transversal direction.

\subsection{Simulation results (the SHPP out of service)}

First, the Small HydroPower Plant SHPP [13] was considered to be out of service, i.e., scenarios I-VII. The simulated results of these scenarios are graphically represented and compare each other's transverse and longitudinal components of the velocities in the sections evaluated.

In Fig. 4-Fig. 7 it can be seen that the course of both the transverse and longitudinal components of the velocities in the section above the upper lock approach is different from the course below the lower lock approach. This is caused by the formation of an eddy below the lower lock approach. For this reason, the components of the velocities achieve positive as well as negative values. The sign shows the orientation of the velocity vector. When it is positive, the velocity vector is oriented towards an axial 
direction and vice versa. An eddy is formed in all the scenarios, and its parameters depend on the method of passing the flow over the WS.

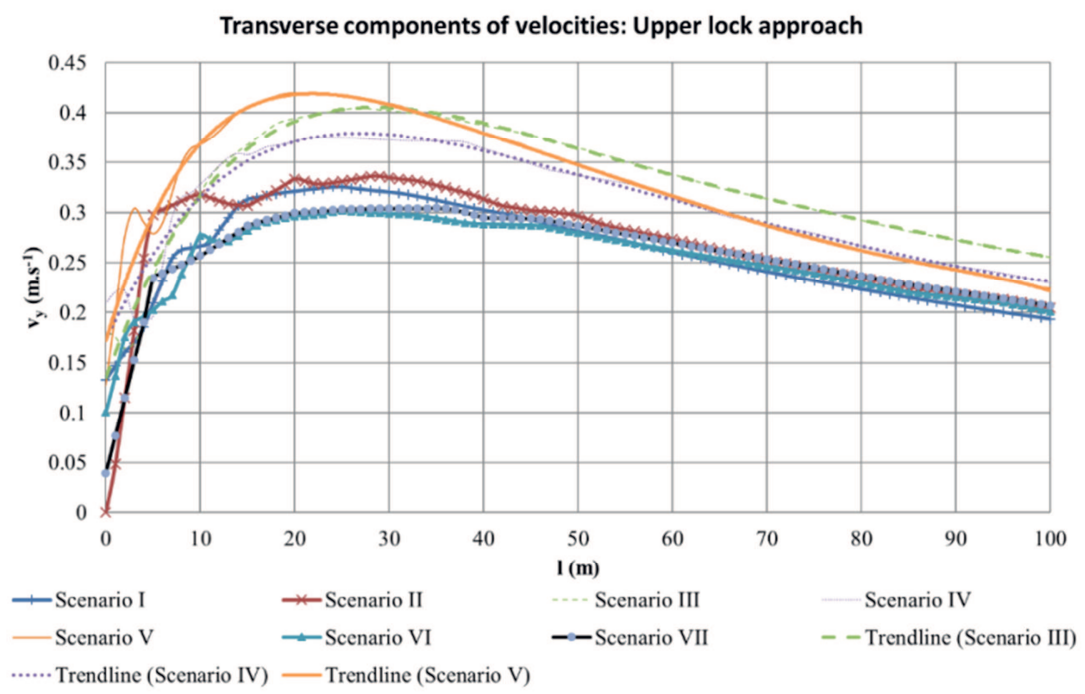

Fig. 4. Course of the transverse components of the velocities in the section above the upper lock approach

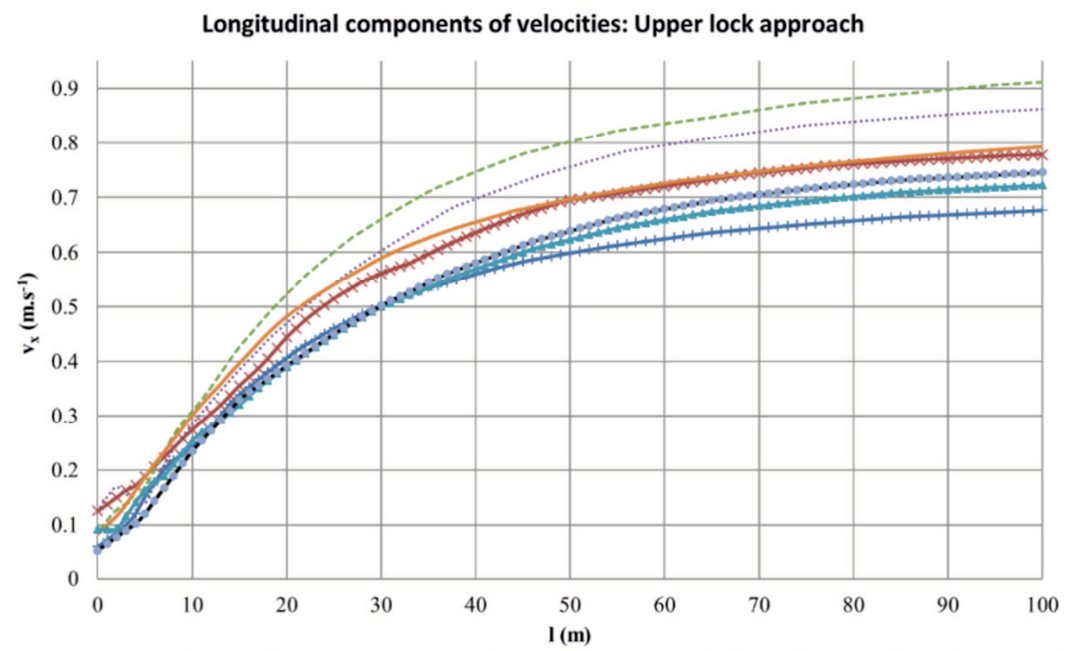

-Scenario I $\because$ Scenario II ----Scenario III …… Scenario IV - Scenario V $\leadsto$ Scenario VI - -Scenario VII

Fig. 5. Course of the longitudinal components of the velocities in the section above the upper lock approach

Pollack Periodica 11, 2016, 3 




Fig. 6. Course of the transverse components of the velocities in the section below the lower lock approach

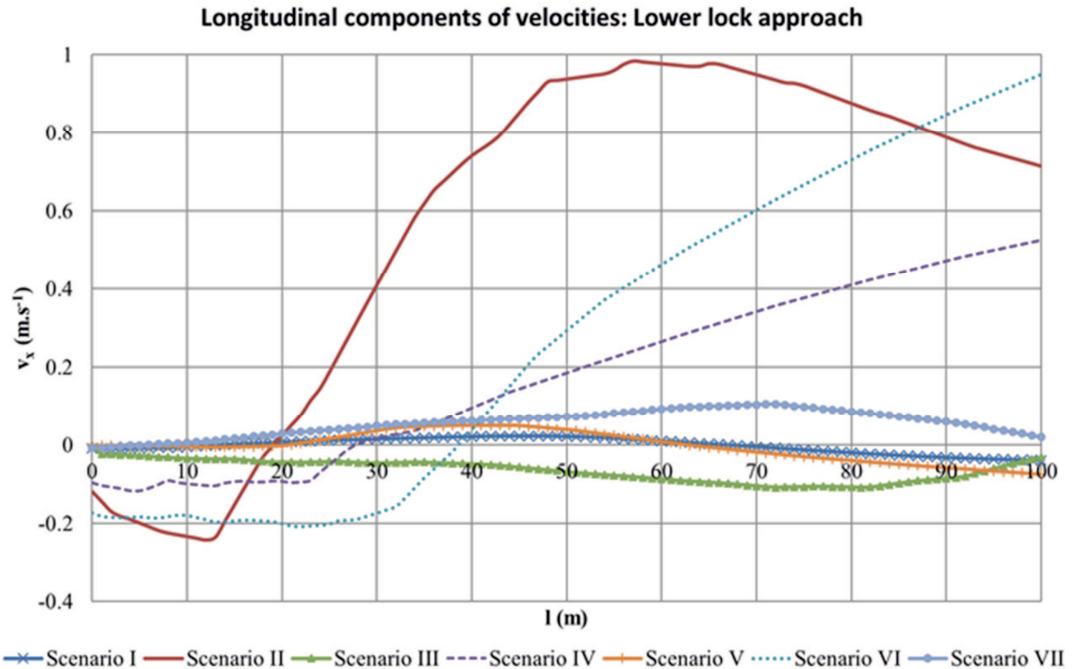

Fig. 7. Course of the longitudinal components of the velocities in the section below the lower lock approach

As Fig. 4 shows, the limit value of the transverse components of the velocities in the section above the upper lock approach is surpassed in all the scenarios of passing the highest navigable flow. These components of the velocities take the highest values of 20 
- $30 \mathrm{~m}$ before the entrance to the lock approach. In the case of the upper lock approach, the longitudinal components of the velocities do not constitute a threat, since they do not enter into the too high values and decrease towards the lock approach entrance to values between $0.05-0.15 \mathrm{~m} \cdot \mathrm{s}^{-1}$.

In the section below the lower lock approach, the course of the velocity components depends on the eddy and varies highly in almost every scenario (Fig. 6, Fig. 7). However, the transverse (Fig. 4, Fig. 6) and longitudinal (Fig. 5 and Fig. 7) components of the velocities do not assume values unsuited to navigational safety, except for the scenario of passing the flow over the fixed and gated weir of the WS in its current state (Scenario II).

Table II summarizes the most favorable and unfavorable scenarios of passing the flow over the Selice WS with regard to the impact of the velocity field on navigational safety. In the parentheses the second most favorable scenario can be seen, so it can be seen that considering all the circumstances, the most favorable scenario is passing the flow only over the fixed weir in its current state (Scenario I). However, this scenario also shows that the transverse components of the velocities in the area of the upper lock approach are too high while passing the highest navigable flow [14]. They can be reduced by an elongation of the lock approach walls or by a modification of the cross section.

Table II

Summarization of the simulation results with the SHPP out of service

\begin{tabular}{|l|c|c|}
\hline & The most favorable & $\begin{array}{c}\text { The most } \\
\text { unfavorable }\end{array}$ \\
\hline $\begin{array}{l}\text { Transverse components of velocities: } \\
\begin{array}{l}\text { Upper lock approach } \\
\text { Longitudinal components of velocities: }\end{array}\end{array}$ & $\begin{array}{l}\text { Scenario IV } \\
\text { (Scenario I) } \\
\text { Scenario I }\end{array}$ & Scenario V \\
$\begin{array}{l}\text { Upper lock approach } \\
\begin{array}{l}\text { Transverse components of velocities: } \\
\text { Lower lock approach }\end{array}\end{array}$ & $\begin{array}{l}\text { Scenario III } \\
\text { (Scenario I) } \\
\text { Lower lock approach }\end{array}$ & Scenario II \\
\hline
\end{tabular}

\subsection{Simulation results (Impact of SHPP operation)}

The impact of the SHPP's operation is demonstrated by the comparison of Scenario VIII (the passing of the highest turbine discharge through the SHPP and the rest of the highest navigable discharge over all the gates of the gated weir of the Selice WS in its projected state) with Scenario III (the passing of the whole highest navigable flow over all the gates of the gated weir of the Selice WS in its projected state).

The simulated results (Fig. 8-Fig. 11) show the negative impact of the SHPP operations on navigational safety, especially in the case of evaluation of the transverse velocity components (Fig. 8, Fig. 10). 


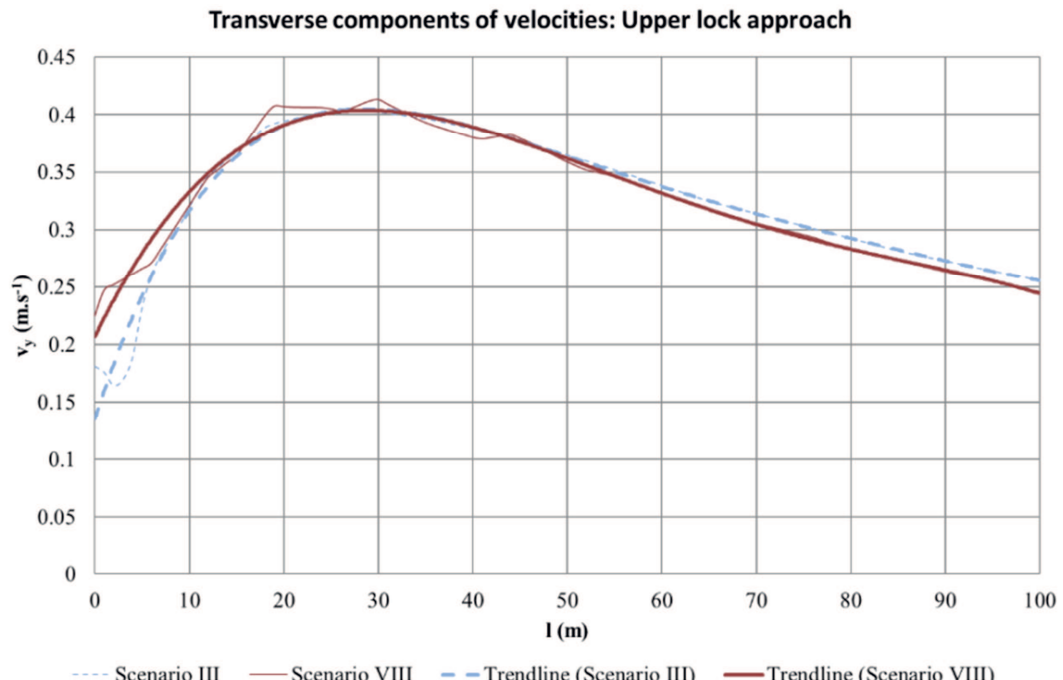

Fig. 8. Course of the transverse components of the velocities in the section above the upper lock approach (Impact of SHPP operation)

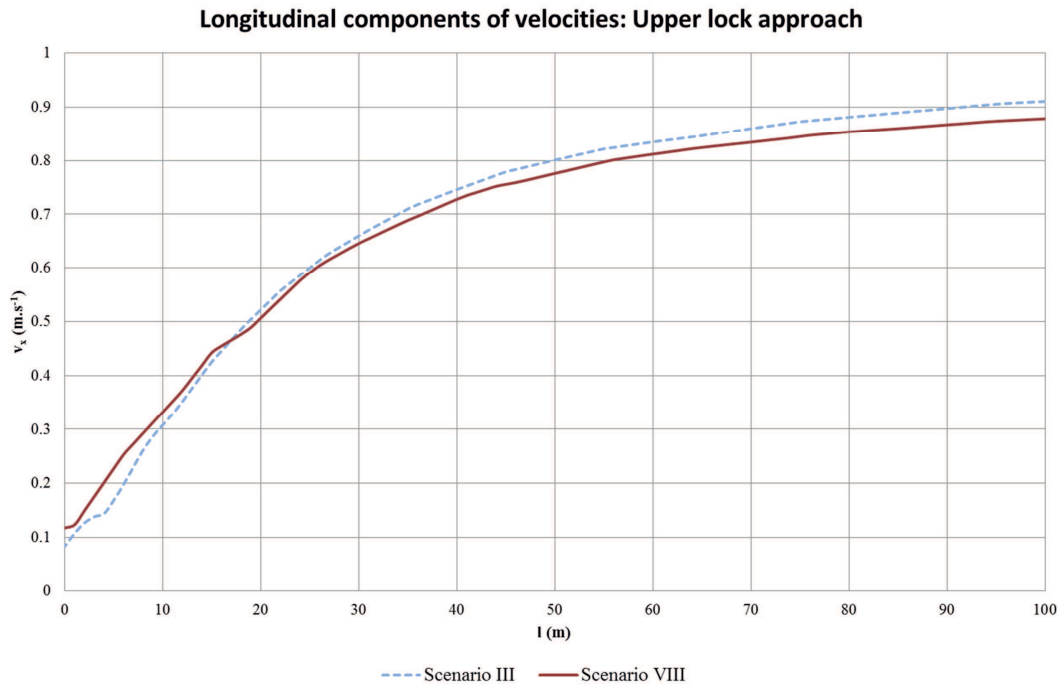

Fig. 9. Course of the longitudinal components of the velocities in the section above the upper lock approach (Impact of SHPP operation) 


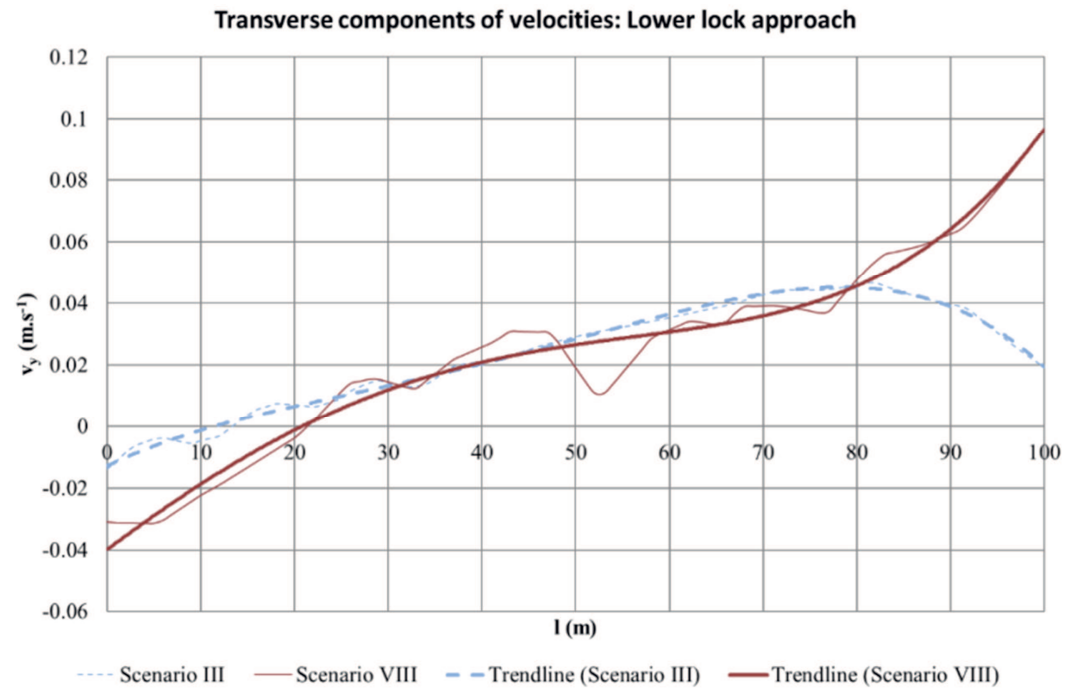

Fig. 10. Course of the transverse components of the velocities in the section below the lower lock approach (Impact of SHPP operation)

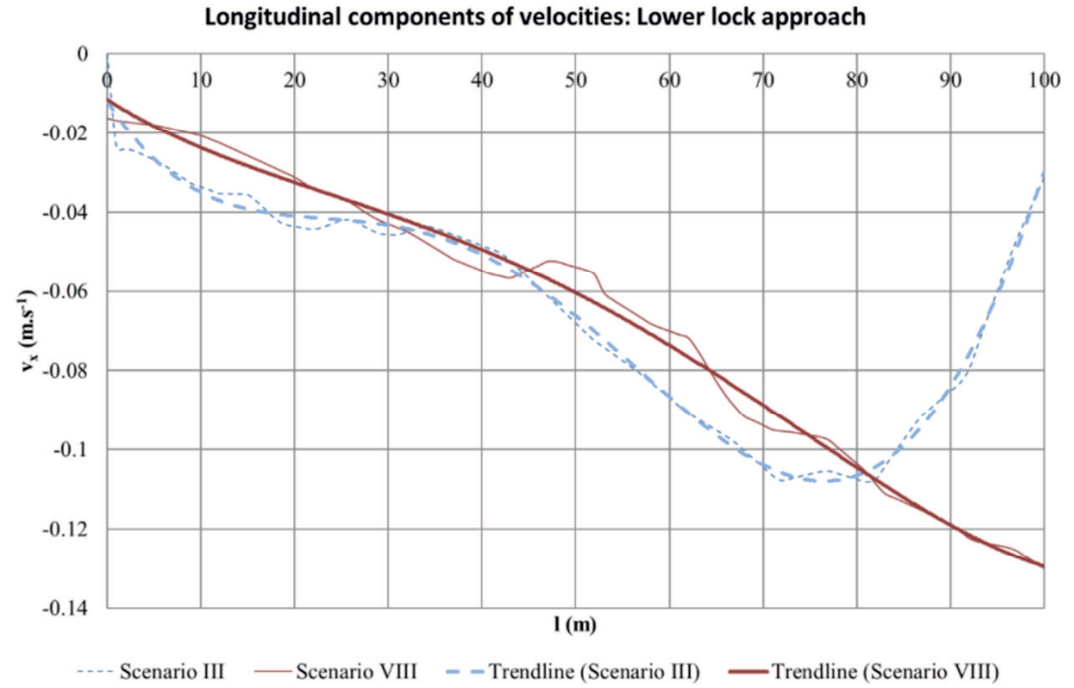

Fig. 11. Course of the longitudinal components of the velocities in the section below the lower lock approach (Impact of SHPP operation) 


\section{Conclusion}

The simulation results mainly point to the problem of the transverse velocity components in the area of the upper lock approach, but also to the disadvantages of the current design of the layout of the WS compared to the projected one. Although, in term of navigational safety, it is generally most favorable to pass the highest navigable flow only over the fixed weir of the WS in its current state, once other structures start to participate in the passing of the flow, the transverse components of the velocities increase to surpass the limit values in the area of the lower lock approach.

In the projected state, no scenario of passing the flow over the WS is problematic in the section below the lower lock approach. In this state, the most favorable scenario is to pass the flow over the fewest number of gates possible. That causes a higher backwater level, thereby resulting in smaller velocities in the upper lock approach entrance area.

The Váh River in the section of the Selice WS should be navigable according the demands of the Classification of European Inland Waterways, it means, the navigational safety should be ensured according to this classification. As the Váh River classification in this section is VIa, the navigational safety should be investigated for the vessels with draught $2.50-4.50 \mathrm{~m}$. River2D model produces a depth-averaged velocity field and assuming a logarithmic profile, it can be shown that the depth-averaged velocity is numerically close to the velocity observed at $30 \%$ of water depth. For the navigational safety, it is advisable to know the velocities affecting the vessel along its whole drought. Seeing that the maximal feasible vessel draught extends deeper than the $30 \%$ of water depth, the using of the two dimensional mathematical modeling is in this case applicable. It pointed to the problem and possibilities of the more complex three dimensional modelling could be used in the following part of the research.

In conclusion it can be stated that to design and build water structure with navigational operations without anterior hydraulic research is highly risky.

\section{Acknowledgements}

This work has been undertaken as a part of a project founded by the Faculty of Engineering and Information Technology, University of Pécs.

This publication is the result of the project implementation: 'Center of Excellence of Integrated Flood protection of Territory', ITMS 26240120004, supported by the Research \& Development Operational Programme funded by the ERDF.

This work is supported by VEGA project No. 1/0660/12.

\section{References}

[1] Kinczer T., Šulek P. Optimalization of operation of regulatory hydropower plants using heuristic methods, In Proceedings of International PdD Students Conference, Colloquium on Landscape Management, Brno, Czech Republic, Mendelova Univerzita v Brně, 18 December 2014. CD-ROM, pp. 16-21. 
[2] Šulek P., Kinczer T., Dušička P. Influence of genetic algorithms parameters on the optimization of hydrothermal coordination problem, In 14th International Symposium on Water Management and Hydraulic Engineering, Institute of Water Structures, Faculty of Civil Engineering, Brno University of Technology, Brno, Czech Republic, 8-10 September 2015, pp. 570-579.

[3] Thorenz, C.; Vantorre, M.; Weiler, O.; Hunter, P.; Roux, S.; Peng, W.; Bousmar, D.; Dubbelman, J. P.; Jun, L.; Spitzer, D.; Veldman, H.; Augustijn, J.; Kortlever, W.; Hartley, A.; Salas, R.; Wong, J. PIANC Working Group 155, Ship behavior in locks and lock approaches, German contributions to the 33rd PIANC World Congress, San Francisco, 1-5 June, 2014, pp. 17-24.

[4] Možiešik L. Roadsteads of the lock-chambers on the navigable streams. Bratislava, Nakladatel'stvo Slovenskej Technickej Univerzity, 2012.

[5] Ultmann Z. Comparing different mass models to the water level fluctuations of the river Danube, Pollack Perodica, Vol. 6, No. 3, 2011, pp. 107-114.

[6] Stefler P., Blackburn J. River2D, Two-dimensional depth averaged model of river hydrodynamics and fish habitat, Introduction to depth averaged modeling and User's Manual, Alberta, University of Alberta, 2002.

[7] Simões F. Finite volume model for two-dimensional shallow environmental flow, Journal of Hydraulic Engineering, Vol. 137, No. 2, 2011, pp. 173-182.

[8] Martin S., Savant G., McVan D. Two-dimensional numerical model of the Gulf Intracoastal Waterway near New Orleans, Journal of Waterway, Port, Coastal and Ocean Engineering, Vol. 138, No. 3, 2012, pp. 236-245.

[9] Možiešik L., Šulek P., Orfánus M. Kolárovo water structure, Preparation of the research and design proposals in SGEM 2014, GeoConference on Water Resources, Forest, Marine and Ocean Ecosystem, STEF 92, Vol. I, Sofia, Bulgaria, 17-26 June 2014, pp. 447-454.

[10] https://www.unece.org/fileadmin/DAM/trans/main/sc3/European_inland_waterways__2012.pdf, (last visited 9 November 2015).

[11] https://en.wikipedia.org/wiki/Classification_of_European_Inland_Waterways, (last visited 9 November 2015).

[12] http://www.sps.sk/jweb/_files/dokumenty/Legislativa/priloha_3_tabulka_1.pdf, (last visited 9 November 2015).

[13] Tkáč Š., Sečka L., Vranayová Z. Hydro-energy in Slovak Republic and Taiwan R.O.C., Pollack Perodica, Vol. 9, No. 3, 2014, pp. 59-70.

[14] Pavlíková A. Hydraulic and stability aspects of nautical grade Selice on Váh, MSC Diploma Thesis, Department of Hydraulic Engineering, Slovak University of Technology in Bratislava, 2015. 